\title{
Giving Patterns By Religious And Non-Religions People
}

Walter O. Simmons, John Carroll University, USA Rosemarie Emanuele, Ursuline College, USA

\begin{abstract}
Using the Oaxaca-Blinder (1994) decomposition method to compare the giving levels of money and time of those who claim to attend religious services on a regular basis with those who do not, we find that on average religious people donate more money and time than non-religious people; although a large portion of the average difference is unexplained. We propose that these differences arise from a culture of giving in which religious people are embedded. It may be that individuals who are religious are more likely to be exposed to a culture that encourages giving and volunteering, and will therefore be more likely to give and volunteer.
\end{abstract}

Keywords: Religious and Non-Religious Giving; Religious and Non-Religious Volunteering

\section{INTRODUCTION}

hen future president George H.W. Bush ran for president in 1998, he coined a phrase to describe his
vision of the nonprofit sector's expansion to assume responsibility for the provision of services
formerly provided by the government: "one thousand points of light." Years later, his son, George W. Bush expanded this idea by predicting that faith-based organizations would be particularly efficient at providing such services, and created the "Office of Faith-Based Initiatives." Does the evidence confirm that religious affiliation is strongly and positively related to philanthropic giving, or is this simply an assumption that society has held for many years? There are those who believe that individuals who are religious are more likely to be exposed to a culture that encourages giving and volunteering, and will therefore be more likely to give and volunteer. Alternatively, those who are religious may be more likely to feel that they need to give money and time to their respective congregations, therefore having less to donate to other groups.

This paper looks at giving and volunteering by individuals who are "religious" and asks if their level of giving is different from that of giving by those who are not "religious." We analyze a survey on philanthropic donations that ask whether donors attend religious services at least twice a month, we then examine contributions of money and volunteer time to nonprofit organizations using the Oaxaca (1973) and Blinder (1973) decomposition method to compare the giving levels of those who claim to attend religious services on a regular basis with those who do not.

\section{LITERATURE REVIEW}

Previous research looking at donations of cash used many of the traditional wage equation variables to explain the level of money donations by individuals (Steinberg et al 2001; Brown and Lankford, 1992; Preston, 1989; Weisbrod, 1987). These studies include such variables as education, experience and age, as well as income level of the donor. In addition, research on donations has included variables to control for the donor's income tax situation, such as whether they are a home owner, and variables to control for their upbringing, such as whether their parents gave to charities. One such variable that is often included is a variable asking about the donor's religious commitment. A survey of the literature shows that the effect of this variable is indeterminate.

Some studies on donations of money and time find that religious donors are likely to give greater levels of money and time to charitable organizations (Menchick and Weisbrod, 1987). This positive relationship may arise 
because most organized religions teach a concern for those less well off. We would expect that those who regularly attend religious services would be regularly exposed to a sub-culture that reinforces this concern for those who are less well off. This increases the probability of religious people being altruistic, and also increases the level of altruism in religious people.

Other research has found that there is a negative relationship between whether a person is religious and the amount of money or time they donate (Simmons and Emanuele (2007)). Their study propose that the negative relationship may be due to the fact that religious people may view tithing, or regularly giving to their congregations, as others might view a tax. This produces a pure (and negative) income effect, leading them to donate less to organizations that might need their money.

\section{EMPIRICAL FRAMEWORK}

The major objective of this study is to analyze differences in the donation of money and time between religious and nonreligious people based on the impact of identical variables on the donation of money and time. To analyze the impact of various variables on the donation of money and time we estimate the following model separately for religious (r) and nonreligious (nr) people:

$\mathrm{D}_{\mathrm{ig}}=\mathrm{X}_{\mathrm{ig}} \beta \mathrm{g}+\varepsilon_{\mathrm{ig}}$

For $g=r$, nr, where $D_{i g}$ refers to the money and time donation of individual $i$ in group $g$. The $X_{i}$ are the explanatory variables. Since donations of money or time are not at a level less than zero, the appropriate statistical technique to use is a censored model. Tobit regressions are estimated to determine the effects of a variety of explanatory variables in inducing religious and nonreligious people to donate money and time. Tobit regressions specify that the dependent variable is truncated in that it may not be less than zero. Two equations are used, to facilitate empirical distinction between time and money decisions and because the decision processes involved can be assumed as not exactly the same; donation of time is assumed as not tax deductible, while the donation of money is. However, the tax system does not distort the allocation of time between volunteer labor and paid labor time. While donation of time is not tax deductible, the earnings that could have been obtained by supplying more time to the paid labor market, rather than to volunteering, is also not taxed. We use identical explanatory variables in both equations since these two decisions are made based on the same money and time constraints.

The second analysis makes adjusted comparisons by asking to what extent we can explain the difference between giving and volunteering between religious and nonreligious people. It is likely that we cannot explain all of the variation in giving and volunteering by religious and nonreligious people and must conclude that some of the difference is caused by variables that are unobservable. To determine the differences in giving and volunteering between religious and nonreligious people we use a technique developed by Blinder (1973) and Oaxaca (1973), generalized and widely applied to studies that analyze racial and gender differentials in wage earnings (Cotton (1988); Oaxaca and Randsom (1994) and Altonji and Black (1999). The Blinder-Oaxaaca method allows the decomposition in the outcome variable between two groups into a portion that is explained by differences in observable characteristics and a portion that is due to differences in unexplained endowed components. Buer and Sinning (2005); Fairlie (1999, 2003); Gomulka and Stern (1990) have extended the traditional decomposition technique to models with censored outcomes and limited dependent variables. The decomposed model based on the specification from equation 1 is:

$\left(\mathrm{R}_{\mathrm{R}}-\mathrm{R}_{\mathrm{N}}\right)=\left(\alpha_{\mathrm{R}}+\mathbf{X}_{\mathrm{R}} \boldsymbol{\beta}_{\mathrm{R}}\right)-\left(\alpha_{\mathrm{N}}+\mathbf{X}_{\mathrm{N}} \boldsymbol{\beta}_{\mathrm{N}}\right)$

Where $\mathbf{X}$ and $\boldsymbol{\beta}$ are the vectors of mean levels of the independent variables and parameter estimates, respectively and $\mathrm{C}_{\mathrm{M}}$ and $\mathrm{C}_{\mathrm{F}}$ are the average cash donation by each sex. Equation 2 can be decomposed to:

$$
\left(\mathrm{R}_{\mathrm{R}}-\mathrm{R}_{\mathrm{N}}\right)=\left(\mathbf{X}_{\mathrm{R}}-\mathbf{X}_{\mathrm{N}}\right) \boldsymbol{\beta}_{\mathrm{R}}+\left(\alpha_{\mathrm{R}}-\alpha_{\mathrm{N}}\right)+\left(\boldsymbol{\beta}_{\mathrm{R}}-\boldsymbol{\beta}_{\mathrm{N}}\right) \mathbf{X}_{\mathrm{N}}
$$

The first term on the right of equation 3 is the difference between the mean levels of donation characteristics times the vector of coefficients. It is part of the giving gap that is attributable to differences between religious and nonreligious people due to observable characteristics such as income, experience, household situation 
and behavior. The second term on the right is a sum of two values. The first is the difference between the intercept terms from the two regressions. The second is the $\mathbf{X}$ weighted differences in parameter estimates. It is the portion of the gross giving gap that cannot be attributed to differences between religious and nonreligious donors in their unobservable characteristics, and is considered to be unexplained. As the intercept terms are also expressing information that is not otherwise explained, the sum of these two terms on the right is considered unexplained.

\section{DATA, DONATION AND TIME ESTIMATES}

To determine the effect of being religious on donations of time and money, we use data from the 2001 wave of the Independent Sector's data "Giving and Volunteering." This data set is the American "gold standard" in the study of philanthropy, and is used in much of the statistical research conducted on the nonprofit sector. It is important to note that this data set is derived from donors in the United States, and therefore can be expected to reflect the particular tax incentives found in the U.S. For example, in the U.S., donations of money are tax deductible, while donations of time are not, and nonprofits in the U.S. are constrained to act in ways that preserve their tax-exempt status. While not a true random sample, the data set attempts to collect a representative sample of people in the United States, and therefore minimizes many of the selection bias problems that arise from smaller data sets. This data set lets us create variables for the total amount of money and time each respondent gave in the past year. We then look for the determinants of this giving by using many of the variables commonly used in wage equations. Details of how to create each variable from the survey questions are given in Appendix A.

Table 1: Tobit Estimates-Determinants of Cash Donations

\begin{tabular}{|c|c|c|c|c|c|c|}
\hline \multirow[b]{2}{*}{ Variable } & \multicolumn{3}{|c|}{ Religious } & \multicolumn{3}{|c|}{ Non-Religious } \\
\hline & $\begin{array}{c}\text { Coefficient } \\
\left(\beta_{M}\right)\end{array}$ & T-stat & $\begin{array}{c}\text { Mean } \\
\left(\mathbf{X}_{\mathrm{R}}\right)\end{array}$ & $\begin{array}{c}\text { Coefficient } \\
\left(\beta_{F}\right)\end{array}$ & T-stat & $\begin{array}{l}\text { Mean } \\
\left(\mathbf{X}_{\mathrm{N}}\right)\end{array}$ \\
\hline Cash donation & & & 2140.85 & & & 1957.25 \\
\hline Constant & -6273.03 & -36.09 & & -6005.34 & -32.53 & \\
\hline Income & 52.0427 & $4.82 *$ & 65.7373 & 79.19113 & $12.58 *$ & 67.9543 \\
\hline Children & -1339.00 & $-4.07 *$ & 0.5892 & 1055.060 & 1.46 & 0.5074 \\
\hline Parents gave & 447.952 & 0.94 & 0.5390 & 1433.912 & $2.08 * *$ & 0.4230 \\
\hline Nonprofit & -493.45 & $-5.57 *$ & 0.1354 & 290.6623 & 0.88 & 0.1185 \\
\hline Asked & 3312.92 & $7.79 *$ & 0.6439 & 839.6529 & 1.27 & 0.4946 \\
\hline Married (wed) & -3238.85 & $-14.9 *$ & 0.7542 & -1487.26 & $-1.95 * * *$ & 0.6324 \\
\hline Owned & 1254.808 & $5.59 *$ & 0.7632 & 45.4875 & 0.06 & 0.6912 \\
\hline Experience & 215.249 & $1.86 * * *$ & 23.9874 & -105.467 & -1.15 & 21.2649 \\
\hline Experience-SQ & -3.8767 & $-1.65 * * *$ & 712.565 & 4.59155 & $2.22 * *$ & 577.9102 \\
\hline $\begin{array}{l}\text { Log Likelihood } \\
\text { Sigma }\end{array}$ & \multicolumn{3}{|c|}{-10095} & & \multicolumn{2}{|c|}{-8367} \\
\hline Number of obse & \multicolumn{3}{|c|}{1115} & & \multicolumn{2}{|c|}{936} \\
\hline
\end{tabular}

Table 2: Tobit Estimates-Determinants of the Value of Time Donations

\begin{tabular}{|c|c|c|c|c|c|c|}
\hline \multirow[b]{2}{*}{ Variable } & \multicolumn{3}{|c|}{ Religious } & \multicolumn{3}{|c|}{ Non-Religious } \\
\hline & $\begin{array}{c}\text { Coefficient } \\
\left(\beta_{M}\right)\end{array}$ & T-stat & $\begin{array}{c}\text { Mean } \\
\left(\mathbf{X}_{\mathbf{R}}\right)\end{array}$ & $\begin{array}{c}\text { Coefficient } \\
\left(\beta_{F}\right)\end{array}$ & T-stat & $\begin{array}{c}\text { Mean } \\
\left(\mathbf{X}_{N}\right)\end{array}$ \\
\hline Time donation & & & 0.6645 & & & 0.2880 \\
\hline Constant & -2.4487 & -7.60 & & -3.5323 & -7.74 & \\
\hline Income & 0.0045 & $3.07 *$ & 65.7373 & 0.0031 & $1.84 * * *$ & 67.9543 \\
\hline Children & 0.1975 & $1.27 *$ & 0.5892 & 0.1956 & 0.90 & 0.5074 \\
\hline Parents gave & 0.4044 & $2.89 * *$ & 0.5390 & 0.3583 & 1.77 & 0.4230 \\
\hline Nonprofit & 0.1203 & 0.62 & 0.1354 & 0.8239 & $2.89 * *$ & 0.1185 \\
\hline Asked & 1.5097 & $9.45 *$ & 0.6439 & 1.0794 & $5.07 *$ & 0.4946 \\
\hline Married (wed) & 0.1123 & $0.64 *$ & 0.7542 & 0.3808 & 1.63 & 0.6324 \\
\hline Owned & -0.0269 & -0.14 & 0.7632 & 0.6428 & $2.34 * *$ & 0.6912 \\
\hline Experience & 0.0172 & 0.80 & 23.9874 & -0.0076 & -0.21 & 21.2649 \\
\hline Experience-SQ & -0.0001 & -0.28 & 712.565 & -0.00001 & -0.02 & 577.9102 \\
\hline $\begin{array}{l}\text { Log Likelihood } \\
\text { Sigma }\end{array}$ & & -1315 & & & & \\
\hline Number of obse & & 1115 & & & 93 & \\
\hline
\end{tabular}


Table 1 and 2 display the coefficient estimates from the estimates for the giving of money and time for religious and nonreligious individuals. Also included are the means of the variables. We eliminate all observations with missing values for at least one of the variables used in the analysis, which results in a sample size of 1115 observations for religious people and 936 observations for nonreligious people. The dependent variables of the amount of money and time are created by adding the amount of time and money given to each of several types of organizations to create a total amount of money and time donated.

Since this data set does not contain information that allows us to create a variable representing the wage paid to each donor, we use the variable for the donor's income to control for the opportunity cost of the donor's time. This may be an overstatement for those donors who obtain a large portion of their income from non-labor sources, and may be an understatement for those who are underpaid at their current places of employment, as may be the case for those who work in the nonprofit sector. It is clear that the income levels for religious and nonreligious individuals have a significant effect on cash donation. However, the impact of this variable is larger for non-religious people, perhaps reflecting the fact that religious people have already given to their congregation. The coefficients on the income variable for cash donation indicate that an additional dollar of income is associated with an additional $\$ 52$ and $\$ 79$ of cash donation for religious and non-religions people respectively. For time donation, the income variable is significant (although only marginally so for non-religious people) for both religious and nonreligious people, reflecting a pure income effect on the "warm glow of volunteering" that is stronger for religious people than for non-religious people (Andreoni 1990).

We control for several factors that may affect a donor's tax status. These include whether the respondent is married and whether they own their home. Since donations of money are tax deductable, it is likely that a person's tax status will influence their level of donations of time and money. Married people who are religious are significantly less likely to give money, which is also the case (although marginally so) for married people who are not religious. We note, however, that this effect is stronger for religious people than for non-religious people. Again, this is possibly the result of a pure income effect encountered by religious people, who have already given to their congregation and now need to meet other obligations. Being married has no significant effect on volunteering by either religious or non-religious people. The effect of owning a home and the accompanying tax benefits have a positive effect on giving of money and time for both religious and non-religious people. However, this effect is statistically significant for only religious people. This may be because the marginal effect of donations by religious people will be greater due to the donations already given to their congregation. Home ownership has a positive and significant effect on the donation of time by non-religious people, but not a significant effect for religious people. This may be due to the commitment to one's community that comes with home ownership, a commitment that imitates the commitment to a community that is the root of religious fellowship.

Several variables are included that measure characteristics of an individual's household situation and behavior. A dummy variable representing a person's upbringing is included. This variable asks if the person's parents gave to charity. This variable is derived from answers to the question "did one or both of your parents do any kind of volunteer work in the community." As this variable is based on recollections years later, it is possible that there is some error in the memories of the respondents. However, it is likely that some respondents' memories are biased positively, while others are biased negatively. On average, we would expect this variable to be fairly correct. The variable parents gave has no significant effect on religious people's cash donation, but a significant and positive effect on non-religious people. This is perhaps due to the culture of giving that religious people are already a part of, therefore drawing less influence from their parents' behavior. Non-religious people, who are not part of a structured culture of giving, are more able to be strongly influenced by their parent's actions. However, the variable parents gave has a significant positive effect on volunteering by both religious and non-religious people, suggesting that the influence of seeing one's parent's volunteer has a stronger effect on the individual's giving of time rather than of money.

Affiliation with a nonprofit organization should make one more likely to be altruistic and thus donate more money and time. People who are religious and work for non-profits are significantly less likely to give money. Nonreligious people who work for nonprofits are more likely (but insignificantly so) to give money. People who are non-religious are not already tied into a culture of giving, and therefore working for a nonprofit exposes them to such a culture. Alternatively, people who are religious are already tied into such a culture, and therefore working for 
a nonprofit does not have such an effect. In fact, having already fulfilled their obligations as givers and as underpaid employees of a nonprofit, they are less likely to give cash. Religious people who work for a nonprofit are more likely to give time, but not significantly so. Non-religious people who work for a nonprofit are significantly more likely to give time, perhaps reflecting the immersion into a culture of giving that comes with working for such an organization.

We also control for whether a donor has children under the age of 18 , since having children may expose a donor to a culture that encourages donating, or it may demand so much extra time and money from the respondent that they face greater time and money constraints and therefore choose to give less. Religious people with children tend to give less cash while the relationship of having children with giving for non-religious people is positive but not significant. This perhaps reflects a pure income effect from the fact that religious people have already given and now feel an obligation to support their families. Neither volunteering by religious people nor non-religious people respond significantly to the presence of a child in the family in giving time. This probably reflects the large time commitment involved in raising children.

The variables experience and experience squared are created by subtracting education plus six years from age to create a proxy for experience. Note that age and education are therefore not included as variables in this regression since they are perfectly collinear with the variable experience. For religious people, experience is positive and experience squared is negative (both marginally). This shows a marginal effect of experience that first increases and then decreases, indicating a concave pattern over time. This is to be expected as a person ages in an environment that encourages a culture of giving. For non-religious people, however, giving first declines with experience (and age) but then increases significantly as they grow older, showing a convex pattern as one ages. This possibly reflects the pull of family obligations in middle-age that compete with giving for those not embedded in a culture of giving. Religious people volunteer more as experience (and age) increases, but do so at a decreasing rate, giving a concave pattern. However, neither of these coefficients are statistically significant. Non-religious people, however, give less time with more experience and this amount decreases but at a decreasing rate. Again, neither of these effects is significant.

\section{DECOMPOSITION OF THE GIVING DIFFERENCE}

The results in Table 3 show that on average religious donors seem to give more in both money and time donations but the difference is only significant for time donation. On average donors who claim to be religious donated 8.5 percent $(0.0857603)$ more money and over 50 percent more time $(0.56659)$ than donors who do not claim to be religious. As a result of the large variation in money donation the percentage advantage religious donors possess in money donation is not statistically significant while that of time donation is highly significant.

Table 3: Religious - Nonreligious Difference Test

\begin{tabular}{lcccccc}
\hline & Mean & Mean & Mean & Percent & Standard & Test \\
& Religious & Non-religious & Difference & Difference & Error & Statistics \\
Money Donation & 2140.85 & 1957.25 & 183.6 & 0.0857603 & 1124.142 & 0.3424 \\
Time Donation & 0.6645 & 0.2880 & 0.3765 & 0.5665914 & 0.0377 & $9.984 *$ \\
\hline Stars indicate & & & &
\end{tabular}

Stars indicate significant at the $0.01(*), 0.05(* *)$ and $0.10(* *)$ critical levels

Table 4: Decomposition of Religious and Non-Religious: Money and Time Donation

\begin{tabular}{lcc}
\hline Money Donation & Religious Means & $\begin{array}{c}\text { Evaluated at } \\
\text { Donation Advantage due to }\end{array}$ \\
\hline Characteristics & -0.08 & -0.41 \\
Returns & 1.08 & 1.41 \\
\hline Time Donation & & Evaluated at \\
Donation Advantage due to & Religious Means & Non-Religious Means \\
\hline Characteristics & 0.22 & 0.20 \\
Returns & 0.78 & 0.80 \\
\hline
\end{tabular}

Note: Religious and Non-religious differential are largely unexplained by mean levels of Characteristics. Outcome is based on the decomposition method (equation 3). On average, donors claiming to be religious donated significantly more money and time (approximately) than those who are not religious. 
Tables 4 reports the decomposition of the giving difference between religious and nonreligious based on the specification described in equation 3. The results show how much of the donation of money and time is explained by observable characteristics such as income, experience, family tradition of giving, and asking individuals to give. The means are evaluated for all four possible decomposition outcomes; assuming religious people donate more money, assuming non-religious people donate more money, assuming religious people donate more time, and assuming non-religious people donated more time. According to table 4 all the included characteristics account for -0.08 and -0.41 of money donation when evaluated at religious and non-religious mean levels respectively. Actually, most of the money donation (not shown in table) is accounted for by donors characteristics such as experience, marital status (married) and solicitation to give (ask). A substantial portion (1.08 and 1.41 respectively) of money donation for religious and non-religious donation is unexplained which says that large percent of how much religious and non-religious people donate is not explained by variables used in this model. It implies that unobservable factors (about donor's religious or nonreligious beliefs) play an important role in the giving decisions of individuals.

For the donation of time, the same endowed characteristics explain substantially more (over 20 percent) of the differential when evaluated at religious and non-religious means. The endowed characteristics (not shown in table) solicitation to give (ask) accounts for 69 percent and 54 percent of the impact. However, over 70 percent (78 and 80 percent) of the difference in time donation (evaluated at religious and non-religious means) is not accounted for by the variables included in the model. This is a large percentage and a significant outcome since it suggest that the variables commonly used to explain volunteer labor in the labor market ar not capturing a substantial portion of the variation in volunteer time.

\section{DISCUSSION AND CONCLUSION}

What are the origins of the differences in giving and volunteering between religious people and nonreligious people? We propose that these differences arise from a culture of giving in which religious people are embedded. It may be that individuals who are religious are more likely to be exposed to a culture that encourages giving and volunteering, and will therefore be more likely to give and volunteer. Alternatively, it may be that those who are religious are more likely to feel that they need to give money and time to their respective congregations, therefore having less to donate to other groups.

Studies that examine wage differentials often cite discrimination and culture as the primary causes for unobservable differences in labor market returns (Sowell, 1975, 1981, 1983; Cheswick, 1983; Simmons, 2003). These studies argue that the unexplained differential found in wage disparities between ethnic groups may arise from not only discrimination, but also from cultural characteristics, such as attitudes towards work. In a similar way, religious affiliation, obligation, and altruistic underpinnings may also have effects on the tendency to volunteer and to give money. Those who are brought up in a religious culture may exhibit attitudes and behavior that are more conducive to giving money and time.

Such a culture of giving would encourage donors to act upon "impurely altruistic" motives and donate more time. We propose that volunteering is almost always an impurely altruistic act, as few volunteers have a comparative advantage in the activity in which they volunteer. It would be more efficient for a donor to give money that could be used to hire someone whose comparative advantage is in the volunteer activity. However, instead of giving money, they choose to participate in the activity themselves. We therefore expect religious people to give more time to volunteering than would non-religious people, who are not tied into a culture of giving.

Alternatively, the culture of giving encourages religious people to give money, perhaps in the form of a tithe, to their congregations. Such gifts, which may be seen as obligatory, exert a pure income effect on religious people and therefore lead to lower levels of giving of money to other organizations than may be found by those who are not religious and who therefore do not give to their congregations. It is likely that religious people do not see such giving in the same light as other donations, but regard these donations much as others would regard a tax. We would therefore expect religious people to give less money to other organizations than would non-religious people. Such results are found in previous research where the "religious" dummy variable is used in a multiple regression examining the determinants of time and money (Simmons and Emanuele, (2007)). Overall, the giving of money and time is still greater by religious people. 


\section{AUTHOR INFORMATION}

Walter O. Simmons is Professor and Chairperson in the Department of Economics and Finance, Boler School of Business, John Carroll University. He received his Ph. D in Economics from Wayne State University, in Detroit Michigan. His research interests include issues in international financial centers, labor market discrimination, economics of health care, and the economics of the non-profit sector. E-mail: wsimmons@jcu.edu (Corresponding author)

Rosemarie Emanuele is Professor of Mathematics/Economics at Ursuline College. She received her Ph.D. in economics from Boston College. Her research has concentrated on the economics of the nonprofit sector, including the markets for paid and volunteer labor in this sector. E-mail: remanuele@ ursuline.edu

\section{REFERENCES}

1. Altonji, J., and Black R (1999) "Race and Gender in the Labor Market," in Handbook of Labor Economics, Vol 3C, ed. By O. Ashenfelter, and D. Card. Elsevier Science, Amsterdam.

2. Andreoni, J. (1989). "Giving with Impure Altruism: Applications to Charity and Ricardian Equivalence". Journal of Political Economy 97, pp. 1477-1458.

3. Andreoni, J. (1990). "Impure Altruism and Donations to Public Goods: A Theory of Warm-Glow Giving". Economic Journal 100, pp. 464-477.

4. Blinder, Alan S. "Wage Discrimination: Reduced Form and Structural Estimates." Journal Of Human Resources 8, (1973): 436-455.

5. Brown, Eleanor and Lankford, H. (1992) "Gifts of Money and Gifts of Time: Estimating the Effects of Tax Prices and Available Time", Journal of Public Economics 47, pp. 321-341.

6. Card, David., and Lemieux, Thomas. Wage Dispersion, Returns to Skills, and Black-White Wage Differential, Journal of Econometrics October 1996, 74. 319-361.

7. Cheswick, Barry R. "An Analysis of the Economic Progress and Impact of Immigrants." Report prepared for the Employment and Training Administration, U.S. Department of Labor, 1980.

8. . (1983a. "An Analysis of the Earnings and employment of Asian-American Men" Journal of Labor Economics, 197-214.

9. $\quad$. "Is the New Immigrant Less Skilled Than the Old." Journal of Labor Economics 4, (1986): 168-

192.

10. Cotton, J. “On Decomposition of Wage Differential.” Review Of Economics and Statistics 70, (1988): 235243.

11. Menchick, Paul and B. Weisbrod (1987). "The Supply of Volunteer Labor" Journal of Public Economics, 32, pp. 153-183.

12. Oaxaca, Ronald. "Male-Female Wage Differentials in Urban Labor Markets." International Economic Review 14, (1973): 683-709.

13. Oaxaca, Ronald. and M. Ransom, 1994, "On Discrimination and the Decomposition of Wage Differential." Journal of Econometrics 61, (1994): 5-21.

14. Preston, Ann E. 1989. "The Nonprofit Worker in a for-Profit World" Journal of Labor Economics 17:438463.

15. Sowell, Thomas. Race and Economics. New York: Basic Books, 1973.

16. Sowell, Thomas. Ethnic America. New York: Basic Books, 1981.

17. Sowell, Thomas. "Three Black Histories," In Essays and Data on American Ethnic Groups. Edited by T. Sowell. Washington: The Urban Institute, 1978: 7-64.

18. Steinberg, Richard, Rooney, Patrick, Kathy, Steinberg, and Schervish, Paul (2001), "A Methodological Comparison of Giving Surveys: Indiana as a Test Case," Nonprofit and Voluntary Sector Quarterly, 30, pp. 551-568.

19. Simmons, Walter 2003) "The Black Earnings Gap: discrimination or culture”. The Journal of SocioEconomics, 31, pp. 647-655.

20. Simmons, Walter and Rosemarie Emanuel "Male-Female Giving Differentials: Are Women Naturally More Altruistic?" Journal of Economic Studies Vol. 34 No. 6, pp. 534-550, 2007.

21. Weisbrod, Burton A. 1983. "Nonprofit and Proprietary Sector Behavior: Wage Differentials Among Lawyers" Journal of Labor Economics 1 (3), 246-263. 


\section{APPENDIX A}

\section{Religious}

The respondent answers the question "Do your attend church or synagogue services... "If they respond "every week or nearly every week?" (question Q56 of survey.), they are classified as "religious" with a value of one for this variable. If they do not, they are given a value of zero.

Cash donations are calculated by adding together the responses to question Q23 of the survey. This asks the total amount of money given to a list of twelve types of organizations. They are health organizations, education, religious organizations, human services, environment, public/society benefit, recreation-adults, arts, youth development, private \& community foundations, international/foreign and other.

\section{Volunteer Hours}

The total number of volunteer hours donated is found by adding together the responses to question Q5 of the survey, in which respondents were asked if they had volunteered for a list of 15 possible types of organizations in the past 12 months, past month and/or the past week. These types of organizations are: health organizations, education, religious organizations, human services, environment, public/society benefit, recreation- adults, arts, work related organizations, political organizations, youth development, private \& community foundations, international/foreign, informal-alone, and other.

\section{Income}

The donor's family income is used to represent income in this regression

\section{Children (Child Under 18)}

The respondent answers the question "How many children under 18 are living in your house" (Q 902 of survey) If they answer one or more, they are said to have children under 18 and are given a value of one for this variable.

Parents a dummy variable that equals 1 if an individual's parents gave to charity.

\section{Nonprofit}

Does the respondent work for a nonprofit organization, as determined by question D6A? If so, this value of this variable is one, if not, it given a value of zero.

\section{Ask}

The question V19 reports whether the respondent was asked to volunteer. Note that there is no information in this data set on whether the respondent was asked to give money.

Married

The respondent answers the question "at present, are you"... with "married" being one possible response (question Q905 of survey.) Respondents who answer that they are married are given a value of one for this variable.

\section{Own}

Does the respondent own their own home? This variable is created from Question D7, and is given a value of one if the respondent said "yes" and a value of zero if the respondent said "no". 


\section{Experience}

This variable is created from two responses. The number of years of education is calculated from question Q909 of the survey, asking "What was the last grade or class you completed in school?" This response is added to six and subtracted from the respondent's age to create a proxy for years of experience on the job. We note that this is probably not a perfect value for women, who may lose years of time on the job to take time for child rearing. It would therefore tend to overvalue the amount of experience women actually have.

\section{Experience-SQ}

The variable Experience is squared, experience*experience 
NOTES 